\title{
Do Scarce Precious Metals Equate to Safe Harbor Investments? The Case of Platinum and Palladium
}

\author{
John Francis T. Diaz \\ Department of Finance and Department of Accounting, College of Business, Chung Yuan Christian University, \\ 200 Chung Pei Road, Chungli City 32023, Taiwan \\ Correspondence should be addressed to John Francis T. Diaz; di.jiang@cycu.edu.tw
}

Received 23 July 2015; Revised 29 October 2015; Accepted 29 October 2015

Academic Editor: Jean Paul Chavas

Copyright (C) 2016 John Francis T. Diaz. This is an open access article distributed under the Creative Commons Attribution License, which permits unrestricted use, distribution, and reproduction in any medium, provided the original work is properly cited.

\begin{abstract}
This research establishes the predictability and safe harbor properties of two scarce precious metals, namely, platinum and palladium. Utilizing their spot prices, the study concludes intermediate memory in the return structures of both precious metals, which implies the instability of platinum and palladium returns' persistency in the long run. However, both the ARFIMA-FIGARCH and the ARFIMA-FIAPARCH models confirm long-memory properties in the volatility of the two spot prices. The leverage effects phenomenon is not also present based on the ARFIMA-APARCH and ARFIMA-FIAPARCH models, which may possibly conclude the resilience of both precious metals against increased volatility. However, further tests proved that only platinum has a symmetric volatility response to shocks with the presence of negative gamma parameter, which proves that only platinum can be considered a safe harbor investment, because negative and positive shocks have equal effects on their returns and volatilities. Comparing the four models utilized in this study, the combined ARFIMA-FIAPARCH models are the best fitting model to characterize both precious metals' spot prices.
\end{abstract}

\section{Introduction}

Investors constantly are attracted to precious metals owing to their hedging ability against increasing inflation and economic downturns, and also a means of storing value. The widespread contagion of high volatility in the past major crises (i.e., Subprime Mortgage Crisis and Asian Financial Crisis) has compelled hedgers and speculators to consider alternative investment instruments as part of diversifying investment portfolios to protect them away from increasing risk in stock or other financial markets. As Arouri et al. [1] put it, majority of investors are directed towards precious metals like gold, silver, platinum, and palladium because they offer different returns and volatility directions when financial markets experience signs of instability and are viewed as safe refuge assets in times of crises. Gold and silver are the more popular choices over the years, but investments in platinum and palladium have gained their traction during the recent years that should not be overlooked. The recent surge on their performances is primarily because of their extremely rare reputation, aggravated by the recent mine strikes in
South Africa and perennial political tensions in Russia where the largest mining operations are found. Supply deficits in these rare precious metals are common. In the last two years, demand outpaced supply by $28 \%$ for platinum and by $38 \%$ for palladium. Platinum and palladium production is less than $10 \%$ of gold's production, and their in-ground reserves are approximated to be $50 \%$ to $65 \%$ of gold's reserves, and these scarcity conditions make them trade at a premium over gold and silver and are sought-after investments.

Platinum and palladium are both precious metals, which attract huge jewelers for ornaments or plain store of value, and industrial metals, which have various applications in automobile, electronic, and even dentistry components. Investment analysts argue that the short-term prospects of the metals are bright, because of their relatively current low prices per ounce, which once peaked at US\$2,200/ounce in 2008 for platinum and US\$ 1,100/ounce in 2000 for palladium. Demand is also more likely to rise because of the forecasted increased demand in the automobile industry especially in the emerging markets of China and India because platinum is used primarily for catalytic converters. 
Also, palladium is slowly replacing platinum as a lower-cost material from the past two decades, since it can basically perform the same function as platinum in catalytic converters. However, researchers argue that, in the longer term, platinum might be a better performer than palladium based on Johnson Matthey Plc Executive Summary Report of 2013. The research firm forecasts that gross platinum demand will rise by around $4.9 \%$ to a record of 8.42 million ounces, but gross palladium demand might fall by $3.4 \%$ to 9.63 million ounces because of slowing demand in diesel engines' catalytic converters due to more stern emission regulations.

The performance of these two precious metals as investments in the long run is tested in this study. Understanding return and volatility characteristics of platinum and palladium spot prices is important because persistent changes in their time-series structures can expose investors and hedgers alike to risk especially when weak industry demand and instability of supply occur. Accurate modeling of their time-series return and volatility characteristics can become a major concern if supply deficit continues to increase for platinum and decrease for palladium. The possible spillover to the globalized commodity precious metals markets made scholars and practitioners more interested in knowing the predictability and asymmetric volatility properties of platinum and palladium.

The predictability of precious metals under study can be determined by the positive dependence or the so-called longmemory process, which models the presence of a persistent temporal dependence among distant time-series data in returns and volatility. On the other hand, the asymmetric volatility property of the platinum and palladium data series describes the negative correlation between their returns and innovations in volatility. This property is commonly connected to the leverage effects phenomenon, because negative changes are often followed by future higher volatility than positive innovations. These data characteristics have been seen in stock returns (e.g., $[2,3])$, exchange rates (e.g., $[4,5])$, commodities $[6,7]$, exchange-traded funds (ETFs) (e.g., [8, 9]), and exchange-traded notes (ETNs) (e.g., [10]). However, the literature has yet to characterize the predictability and asymmetric volatility of platinum and palladium spot prices. The study is motivated by the recent surge in the application of fractionally integrated (FI) long-memory and asymmetric volatility models in financial time-series. This research is also inspired by the possible upward momentum in the prices of platinum and palladium because of the steadying supply beginning the second quarter of 2014.

The paper wants to add to the dearth in literature of platinum and palladium prices returns and volatility, particularly statistically establishing their predictable and safe harbor properties as investments. The closest paper that can be identified in the literature is the work of Arouri et al. [1] using ARFIMA-FIGARCH models and was able to determine the long-memory properties of platinum and palladium spot prices. In another related study, Batten et al. [11] found that volatility properties of the two precious metals are close to being a financial market investment more than being a hedge instrument. This research contributes to the literature by comparing four combinations of
FI models, (a) ARFIMA-GARCH, (b) ARFIMA-APARCH, (c) ARFIMA-FIGARCH, and (d) ARFIMA-FIAPARCH, in examining long-term positive dependence and asymmetric volatility properties in the returns and volatility of platinum and palladium price returns. In relation with the motivation and contributions, this paper differs from the previous studies through these four main objectives:

(a) Identifying which type of models is better to characterize future values using lagged returns in the timeseries of platinum and palladium prices.

(b) Finding out positive long-term dependence and examining the dual long-memory process in the two precious metals' returns and volatilities.

(c) Determining differences in the characteristics of platinum and palladium prices with regard to their short-, intermediate-, and long-memory processes.

(d) Providing evidence that may challenge the basic assumptions of the EMH of Fama [12], because the presence of high-order positive correlations makes predictions on future returns possible.

The research is written as follows. Section 2 explains the data and the four fractional integration models applied; Section 3 presents the empirical results; and Section 4 gives the conclusion.

\section{Data and Methodology}

This research analyzes daily London closing prices of platinum and palladium from the Johnson Matthey Base Price database downloaded in Quandl.com website from July 2, 1992, to May 23, 2014. The platinum data has a total of 5,535 data points, and palladium has a total of 5,531 observations. The returns series of both precious metal prices were computed as $y_{t}=100\left(\log p_{t}-\log p_{t-1}\right)$, where $p_{t}$ represents the price at time $t$. The financial time-series data were modeled by ARFIMA-GARCH, ARFIMA-APARCH, ARFIMA-FIGARCH, and ARFIMA-FIAPARCH processes and are explained below.

The ARFIMA $(p, d, q)$ model proposes the difference parameter $(d)$ as noninteger and suggests the FI process $I(d)$ in the conditional mean. The model was introduced by Granger and Joyeux [13] and Hosking [14], which offered the initial testing of the long-memory process. The model complies with both stationary and invariability conditions and can be represented as

$$
\begin{aligned}
\phi(L)(1-L)^{d}\left(X_{t}-\mu\right)=\theta(L) & \varepsilon_{t}, \\
& \varepsilon_{t}=z_{t \sigma_{t^{\prime}}}, z_{t} \sim N(0.1),
\end{aligned}
$$

where $d$ denotes a fractional integration real number parameter, $\mu$ corresponds to the conditional mean, $L$ represents the lag operator, and $\varepsilon_{t}$ denotes a white noise residual. The $(1-L)^{d}$ function corresponds to the fractional differencing lag operator. The AR and the MA processes have all roots outside the unit circle and can be shown as $\phi(L)=1-\phi_{1} L-\phi_{2} L^{2}-$ $\cdots-\phi_{P} L^{p}$ and $\theta(L)=1-\theta_{1} L-\theta_{2} L^{2}-\cdots-\theta_{P} L^{p}$, respectively. 
The ARFIMA model is said to be stationary when $-0.5<$ $d<0.5$, where the effect of shocks to $\varepsilon_{t}$ decays at a gradual rate to zero. The model becomes nonstationary when $d \geq$ 0.5 and stationary but a noninvertible process when $d \leq$ -0.5 , which means that the data time-series is impossible to model by any AR process. With regard to the modeling of data dependencies, the ARFIMA model represents a short memory if $d=0$, where the effect of shocks decays geometrically; and a unit root process is shown when $d=1$. Furthermore, the model has a positive dependence among distant observations or the so-called long-memory process if $0<d<0.5$; and it also has an antipersistent property or has an intermediate memory if $-0.5<d<0$.

The GARCH $(p, q)$ model estimates the AR model and computes the autocorrelations of error terms. The model was introduced by Bollerslev [15] as a generalization of Engle's [16] ARCH model. The model assumes that the returns process is expressed as an AR process of order $k$ :

$$
r_{t}=\varsigma_{0}+\sum_{i=1}^{k} \varsigma_{i} r_{t-i}+\varepsilon_{t} .
$$

A GARCH model can be expressed as follows based on information featured in time $t-1$, with $\varepsilon_{t}$ being an iid random variable with mean 0 and variance $\sigma_{t}^{2}$ :

$$
\sigma_{t}^{2}=\omega+\sum_{i=1}^{q} \alpha_{i} \varepsilon_{t}^{2}+\sum_{j=1}^{p} \beta_{j} \sigma_{t-j}^{2}
$$

The lag operator can indicate the GARCH model as

$$
\sigma_{t}^{2}=\omega+\alpha(L) \varepsilon_{t}^{2}+\beta(L) \sigma_{t}^{2},
$$

where $\alpha(L)=\alpha_{1} L+\alpha_{2} L+\cdots+\alpha_{q} L^{q}$ and $\beta(L)=\beta_{1} L+\beta_{2} L+$ $\cdots+\beta_{p} L^{p}$.

The GARCH model is consistent with a short-memory model having its autocorrelation function decaying slowly with a hyperbolic rate [15].

The APARCH $(p, q)$ model integrates a power term in its structure that emphasizes periods of relative tranquility and volatility by magnifying the outliers in the time-series. The APARCH model was introduced by Ding et al. [17] estimating the optimal power term rather than imposing a structure on the data. The APARCH model can be expressed as

$$
\sigma_{t}^{\delta}=\alpha_{0}+\sum_{i=1}^{q} \alpha_{i}\left(\left|\varepsilon_{t-i}\right|-\gamma_{i} \varepsilon_{t-i}\right)^{\delta}+\sum_{j=1}^{p} \beta_{j} \sigma_{t-1}^{\delta},
$$

where $\alpha_{0}>0, \delta \geq 0, \beta_{j} \geq 0, \alpha_{i} \geq 0$, and $-1<\gamma_{i}<1$.

The APARCH model offers the flexibility of a varying exponent $\delta$ with the asymmetry coefficient $\gamma_{i}$ to account for the leverage effect. The model can be reduced to the ARCH model when $\delta=2, \gamma_{i}=0(i=1, \ldots, p)$, and $\beta_{j}=0$ $(j=1, \ldots, p)$; GARCH model when $\delta=2$ and $\gamma_{i}=0$ $(i=1, \ldots, p)$; and the GJR when $\delta=2$.

The FIGARCH $(p, d, q)$ model extends the traditional GARCH model and allows the distinguishing parameter $(d)$ to be noninteger. The model was introduced by
Baillie et al. [18], which offers greater flexibility by capturing short, intermediate, and long memory in the volatility of financial time-series. The FIGARCH model can be expressed as

$$
\left[\phi(L)(1-L)^{d}\right] \varepsilon_{t}^{2}=\omega+[1-\beta(L)]\left(\varepsilon_{t}^{2}-\sigma_{t}^{2}\right),
$$

where $d$ represents a fractional integration parameter, $L$ denotes the lag operator, and $\varepsilon_{t}$ corresponds to a white noise residual process; $(1-L)^{d}$ represents the fractional differencing operator; and $\phi(L)$ denotes an infinite summation, which has to be truncated. The model has a long-memory process when $0<d<1$, which allows more flexibility in modeling the conditional variance rather than the mean. The FIGARCH process is reduced to the GARCH model when $d=0$.

The FIAPARCH $(p, d, q)$ model also extends the GARCH process by capturing volatility asymmetry aside from the long-memory attribute in the conditional variance. The model was introduced by Tse [19] and is considered superior to the FIGARCH process through the improvement in volatility with the function $\left(\left|\varepsilon_{t}\right|-\gamma \varepsilon_{t}\right)^{\delta}$, which can be written as follows:

$$
\begin{aligned}
\sigma_{t}^{\delta}= & \omega[1-\beta(L)]^{-1} \\
& +\left\{1-[1-\beta(L)]^{-1} \rho(L)(1-L)^{d}\right\}\left(\left|\varepsilon_{t}\right|-\gamma \varepsilon_{t}\right)^{\delta},
\end{aligned}
$$

where $d$ corresponds to the fractional integration parameter and gamma $(\gamma)$ represents the asymmetry model parameter. The model assumes a long-memory process when $0<d<$ 1 and determines if negative shocks have more impact on volatility than positive shocks when $\gamma>0$. The FIAPARCH process can be reduced to the FIGARCH model if $\gamma=0$ and $\delta=2$.

\section{Empirical Results}

Table 1 shows that both precious metals prices have positive returns with palladium having slightly higher returns with 0.018 than platinum with 0.011 . Palladium returns are also more significantly volatile with 0.910 compared to 0.607 of platinum, which is attributed to (a) relative rarity of the metal; (b) declining use in catalytic converters of diesel engines, because of stricter emissions tests; and (c) unstable production location in Russia in which $44 \%$ are produced, compared to $13 \%$ of platinum. The research concludes that the Modern Portfolio Theory of Markowitz [20], stating that a higher risk is compensated with higher returns, is consistent with the two precious metals under study. Moreover, platinum returns are negatively skewed, while palladium returns are positively skewed, but both have leptokurtic distributions. The Jarque-Bera statistic for residual normality shows that the precious metals' returns are under a nonnormal distribution assumption.

Table 2 illustrates the use of Augmented Dickey-Fuller test to examine the stationarity of the platinum and palladium returns and the minimum value of the Akaike Information Criterion to identify the orders of the models. Both precious metals' returns have no serial correlation, based on the results 
TABLE 1: The sample size and period of London gold price fixing.

\begin{tabular}{lccccccc}
\hline Precious metals & Start of data & Daily obs. & Mean & Std. dev. & Skew. & Kurt. & J-Bera \\
\hline Platinum & July 2, 1992 & 5,535 & 0.011 & 0.607 & -0.288 & 13.834 & $271456^{* * *}$ \\
Palladium & July 2, 1992 & 5,531 & 0.018 & 0.910 & 0.031 & 10.749 & $13841^{* * *}$ \\
\hline
\end{tabular}

Note: $*, * *$, and $* * *$ are significant at 10,5 , and $1 \%$ levels.

Source: Quandl website; http://www.quandl.com/.

TABLE 2: Summary statistics of ARMA and GARCH filtering.

\begin{tabular}{lcccccccc}
\hline Precious metals & ADF & ARMA & AIC & LM test & ARCH-LM & GARCH & AIC & ARCH-LM \\
\hline Platinum & $-44.417^{* * *}$ & \multirow{2}{*}{$(1,1)$} & \multirow{2}{*}{1.841} & 0.741 & $243.944^{* * *}$ & $(1,1)$ & 1.508 & 1.565 \\
& $(0.000)$ & & & $(0.476)$ & $(0.000)$ & & $(0.206)$ \\
\multirow{2}{*}{ Palladium } & $-43.978^{* * *}$ & $(2,1)$ & 2.644 & 0.926 & $138.262^{* * *}$ & $(2,1)$ & 2.330 & 1.717 \\
& $(0.000)$ & & & $(0.396)$ & $(0.000)$ & & $(0.180)$ \\
\hline
\end{tabular}

Note: $*, * *$, and $* * *$ are significant at 10,5 , and $1 \%$ levels, respectively; $p$ values are in parentheses.

TABLE 3: (a) Lagged innovations and volatility asymmetry in platinum prices. (b) Lagged innovations and volatility asymmetry in palladium prices.

(a)

\begin{tabular}{|c|c|c|c|c|c|c|c|}
\hline \multirow{2}{*}{ Fractional integration models } & \multicolumn{3}{|c|}{ Mean equation } & \multicolumn{4}{|c|}{ Conditional variance equation } \\
\hline & $\alpha_{0}$ & $\alpha_{1}$ & $\theta_{1}$ & $a_{0}$ & $\alpha_{1}$ & $\psi_{1}$ & $\delta$ \\
\hline ARFIMA-GARCH & $\begin{array}{c}0.020^{* *} \\
(0.011)\end{array}$ & $\begin{array}{l}-0.020 \\
(0.908)\end{array}$ & $\begin{array}{c}0.116 \\
(0.469)\end{array}$ & $\begin{array}{r}0.0111^{* * *} \\
(0.005)\end{array}$ & $\begin{array}{c}0.116^{* * *} \\
(0.000)\end{array}$ & $\begin{array}{c}0.878^{* * *} \\
(0.000)\end{array}$ & \\
\hline ARFIMA-APARCH & $\begin{array}{c}0.025^{* * *} \\
(0.001)\end{array}$ & $\begin{array}{l}-0.018 \\
(0.916)\end{array}$ & $\begin{array}{c}0.110 \\
(0.478)\end{array}$ & $\begin{array}{c}0.013^{* *} \\
(0.012)\end{array}$ & $\begin{array}{c}0.121^{* * *} \\
(0.000)\end{array}$ & $\begin{array}{c}0.889^{* * *} \\
(0.000)\end{array}$ & $\begin{array}{r}1.488^{* * *} \\
(0.000)\end{array}$ \\
\hline ARFIMA-FIGARCH & $\begin{array}{c}0.0181^{* *} \\
(0.022)\end{array}$ & $\begin{array}{l}-0.063 \\
(0.751)\end{array}$ & $\begin{array}{c}0.150 \\
(0.412)\end{array}$ & $\begin{array}{c}0.021^{* * *} \\
(0.006)\end{array}$ & $\begin{array}{c}0.306^{* * *} \\
(0.001)\end{array}$ & $\begin{array}{c}0.535 \\
(0.000)\end{array}$ & \\
\hline ARFIMA-FIAPARCH & $\begin{array}{r}0.020^{* * *} \\
(0.009)\end{array}$ & $\begin{array}{l}-0.069 \\
(0.725)\end{array}$ & $\begin{array}{c}0.157 \\
(0.390)\end{array}$ & $\begin{array}{l}0.018^{*} \\
(0.052)\end{array}$ & $\begin{array}{c}0.307^{* * *} \\
(0.001)\end{array}$ & $\begin{array}{c}0.532^{* * *} \\
(0.000)\end{array}$ & $\begin{array}{r}2.033^{* * *} \\
(0.000)\end{array}$ \\
\hline
\end{tabular}

Note: $*, * *$, and $* * *$ are significant at 10,5 , and $1 \%$ levels, respectively; $p$ values are in parentheses.

(b)

\begin{tabular}{|c|c|c|c|c|c|c|c|}
\hline \multirow{2}{*}{ Fractional Integration Models } & \multicolumn{3}{|c|}{ Mean Equation } & \multicolumn{4}{|c|}{ Conditional Variance Equation } \\
\hline & $\alpha_{0}$ & $\alpha_{1}$ & $\theta_{1}$ & $a_{0}$ & $\alpha_{1}$ & $\psi_{1}$ & $\delta$ \\
\hline ARFIMA-GARCH & $\begin{array}{c}0.010^{* *} \\
(0.015)\end{array}$ & $\begin{array}{c}0.107 \\
(0.605)\end{array}$ & $\begin{array}{l}-0.019 \\
(0.921)\end{array}$ & $\begin{array}{c}0.003^{* *} \\
(0.012)\end{array}$ & $\begin{array}{c}0.095^{* * *} \\
(0.000)\end{array}$ & $\begin{array}{c}0.900^{* * *} \\
(0.000)\end{array}$ & \\
\hline ARFIMA-APARCH & $\begin{array}{c}0.015^{* * *} \\
(0.001)\end{array}$ & $\begin{array}{c}0.068 \\
(0.746)\end{array}$ & $\begin{array}{c}0.014 \\
(0.943)\end{array}$ & $\begin{array}{c}0.005^{* *} \\
(0.010)\end{array}$ & $\begin{array}{r}0.103^{* * *} \\
(0.000)\end{array}$ & $\begin{array}{r}0.907^{* * *} \\
(0.000)\end{array}$ & $\begin{array}{r}1.442^{* * *} \\
(0.000)\end{array}$ \\
\hline ARFIMA-FIGARCH & $\begin{array}{c}0.012^{* * *} \\
(0.006)\end{array}$ & $\begin{array}{c}0.151 \\
(0.431)\end{array}$ & $\begin{array}{l}-0.063 \\
(0.720)\end{array}$ & $\begin{array}{c}0.007^{* *} \\
(0.030)\end{array}$ & $\begin{array}{c}0.309^{* * *} \\
(0.000)\end{array}$ & $\begin{array}{c}0.629^{* * *} \\
(0.000)\end{array}$ & \\
\hline ARFIMA-FIAPARCH & $\begin{array}{c}0.015^{* * *} \\
(0.001)\end{array}$ & $\begin{array}{c}0.153 \\
(0.402)\end{array}$ & $\begin{array}{l}-0.065 \\
(0.700)\end{array}$ & $\begin{array}{l}0.010^{* *} \\
(0.040)\end{array}$ & $\begin{array}{c}0.290^{* * *} \\
(0.000)\end{array}$ & $\begin{array}{c}0.658^{* * *} \\
(0.000)\end{array}$ & $\begin{array}{c}1.880^{* * *} \\
(0.000)\end{array}$ \\
\hline
\end{tabular}

Note: $*, * *$ and $* * *$ are significant at 10,5 and $1 \%$ levels, respectively; $p$-values are in parentheses.

of the Lagrange Multiplier (LM) test. This study also used the ARCH-LM process to test the ARCH effect and eliminate heteroscedasticity in the volatility of the data; the test also illustrates that the GARCH models can be applied in both the platinum and palladium price returns.

Tables 3(a) and 3(b) compare the findings of lagged returns and volatilities from the four combinations of models for platinum and palladium spot prices. Majority of the estimated values illustrate that significant lagged conditional variances of $a_{n}$ and $\psi_{n}$ are relatively stronger than those of significant lagged mean returns of $a_{n}$ and $\theta_{n}$. These outcomes suggest that both the short- and long-memory models for both precious metals also consent to the greater influence of volatility on current innovations. However, both the ARFIMA-APARCH and ARFIMA-FIAPARCH models agree that although volatility has stronger effect, there is an absence of the leverage effects phenomenon with the significant positive values of the delta $(\delta)$ parameter. The study concludes that both platinum and palladium may possibly be immune to greater risks brought about by increased volatility, which 
TABLE 4: Summary statistics of ARFIMA-GARCH and ARFIMA-APARCH models.

\begin{tabular}{|c|c|c|c|c|c|c|c|c|c|}
\hline \multirow{2}{*}{ Precious metals } & \multicolumn{4}{|c|}{ ARFIMA-GARCH } & \multicolumn{5}{|c|}{ ARFIMA-APARCH } \\
\hline & $d$-ARFIMA & $\mathrm{ARCH}$ & AIC & Log-likelihood & $d$-ARFIMA & $\mathrm{ARCH}$ & Gamma & AIC & Log-likelihood \\
\hline Platinum & $\begin{array}{c}-0.050^{* *} \\
(0.041)\end{array}$ & $(1,1)$ & 1.507 & -4163.988 & $\begin{array}{c}-0.046^{* *} \\
(0.044)\end{array}$ & $(1,1)$ & $\begin{array}{c}-0.114^{* *} \\
(0.028)\end{array}$ & 1.502 & -4147.927 \\
\hline Palladium & $\begin{array}{c}-0.028^{*} \\
(0.090) \\
\end{array}$ & $(1,1)$ & 2.330 & -6434.194 & $\begin{array}{l}-0.027 \\
(0.323) \\
\end{array}$ & $(2,2)$ & $\begin{array}{l}-0.050 \\
(0.236) \\
\end{array}$ & 2.337 & -6425.245 \\
\hline
\end{tabular}

Note: $*, * *$, and $* * *$ are significant at 10,5 , and $1 \%$ levels, respectively; $p$ values are in parentheses.

TABLE 5: Summary statistics of ARFIMA-FIGARCH and ARFIMA-FIAPARCH models.

\begin{tabular}{|c|c|c|c|c|c|c|c|c|c|c|c|}
\hline \multirow[b]{2}{*}{ Precious metals } & \multicolumn{5}{|c|}{ ARFIMA-FIGARCH } & \multicolumn{6}{|c|}{ ARFIMA-FIAPARCH } \\
\hline & $\begin{array}{c}d- \\
\text { ARFIMA }\end{array}$ & $\mathrm{ARCH}$ & $\begin{array}{c}d- \\
\text { FIGARCH }\end{array}$ & AIC & Log-likelihood & $\begin{array}{c}d- \\
\text { ARFIMA }\end{array}$ & $\mathrm{ARCH}$ & $\begin{array}{c}d- \\
\text { FIGARCH }\end{array}$ & Gamma & AIC & Log-likelihood \\
\hline Platinum & $\begin{array}{c}-0.053^{* *} \\
(0.039)\end{array}$ & $(1,1)$ & $\begin{array}{c}0.482^{* * *} \\
(0.000)\end{array}$ & 1.501 & & $\begin{array}{c}-0.054^{* *} \\
(0.032)\end{array}$ & $(1,1)$ & $\begin{array}{c}0.517^{* * *} \\
(0.000)\end{array}$ & $\begin{array}{c}-0.090^{*} \\
(0.091)\end{array}$ & 1.500 & -4141.053 \\
\hline Palladium & $\begin{array}{c}-0.028 \\
(0.307) \\
\end{array}$ & $(1,1)$ & $\begin{array}{c}0.443^{* * *} \\
(0.000)\end{array}$ & 2.310 & -6380.522 & $\begin{array}{l}-0.028 \\
(0.298)\end{array}$ & $(1,1)$ & $\begin{array}{c}0.440^{* * *} \\
(0.000)\end{array}$ & $\begin{array}{l}-0.029 \\
(0.450)\end{array}$ & 2.322 & -6379.631 \\
\hline
\end{tabular}

Note: $*, * *$, and $* * *$ are significant at 10,5 , and $1 \%$ levels, respectively; $p$ values are in parentheses.

normally affects other instruments like what Niarchos et al. [21] demonstrated in stock markets, Huang and Yang [22] in exchange rates, Xu and Fung [23] in precious metals futures, and Chen and Huang [24] using ETFs.

Table 4 shows the results of the two methodologies with short memory on volatility. The ARFIMA-GARCH models find intermediate memory in the return structures of both platinum (-0.050 significant at the 5\% level) and palladium ( -0.028 significant at the $10 \%$ level) metals, and ARFIMAAPARCH models confirm the result for platinum $(-0.046$ significant at the $5 \%$ level) but fail to establish intermediate memory in palladium because of insignificant result. Findings on the intermediate-memory properties of the two precious metals were initially determined by Arouri et al. [1]. The ARFIMA-APARCH models also claim that platinum has a symmetric volatility response to shocks with the presence of negative gamma ( -0.114 significant at the $5 \%$ level) coefficient. This finding means that negative and positive shocks have equal effects on platinum returns and volatilities, which implies that platinum can be a safe harbor investment able to withstand economic and financial risks. However, this paper cannot conclude the same with palladium prices, because of insignificant result.

These results make a good amount of economic sense, because platinum has more stable demand from the automotive manufacturers, jewelers, and industrial users, which make up $93 \%$ of the demand. Platinum's density, which is twice that of palladium, and extreme durability make it more in demand for heavy industrial use and luxurious jewelries for ornaments and investments. On the other hand, palladium in catalytic converters in diesel engines, which comprises $68 \%$ of palladium's use, has been declining because of more stringent emissions regulations against pollution caused by diesel automobiles. The location of platinum's production is also more stable, $77 \%$ of which come from South Africa and only $13 \%$ comes from Russia, unlike palladium's production of which $40 \%$ comes from South Africa and $44 \%$ from Russia based on the latest report of US Geological Survey of 2012. The political instability in Russia makes the palladium's prices more volatile, while the huge amount of platinum's production in South Africa makes platinum's prices more stable. Empirical results using the short-memory model ARFIMA-APARCH in the volatility contradict the initial findings of Batten et al. [11] in concluding that platinum behaves more like a financial market instrument, which is not immune to economic shocks. However, given the relative scarcity, established demand, and stable supply of platinum, this paper concludes that precious metal can be a safe harbor investment in relation to palladium. Comparing the two short-memory models in volatility, the log-likelihood value consistently points to the combined ARFIMA-APARCH models as the best fitting model to characterize both precious metals' prices compared to utilizing the ARFIMA-GARCH models, which also justifies the symmetric volatility response property of platinum prices.

Table 5 illustrates the results of the two methodologies with long memory on volatility. The ARFIMA-FIGARCH models find intermediate memory in the return structures of platinum ( -0.053 significant at the $5 \%$ level), and this is also confirmed by the ARFIMA-FIAPARCH models $(-0.054$ significant at the $5 \%$ level). However, neither of the models established intermediate memory in palladium because of insignificant results. These findings are again consistent with the initial findings of Arouri et al. [1], which means that returns property of platinum is antipersistent and will more likely change in the succeeding trading periods. Based on the intermediate-memory findings, it is advised that traders, in order to gain abnormal returns, should still be in constant lookout of market corrections. Furthermore, both the ARFIMA-FIGARCH and ARFIMA-FIAPARCH models found long-memory properties in the volatility of platinum and palladium (all significant at the $1 \%$ level), which means that their volatility structures are predictable and can pose a challenge against Fama's [12] weak-form 
EMH. The ARFIMA-FIAPARCH models also claim that platinum has a symmetric volatility response to shocks with the presence of negative gamma (-0.090 significant at the $10 \%$ level) coefficient, which is consistent with the earlier findings of ARFIMA-APARCH models. Aside from the consistent findings from the two APARCH models, which contradict the initial conclusions of Batten et al. [11], this result also means that negative and positive shocks have equal effects on platinum returns and volatilities, implying that platinum can be safe harbor investment able to withstand economic and financial risks.

These findings can be again attributed to the more stable demand of platinum from automotive manufacturers, jewelers, and industrial users, because of its extreme durability. Also, being mined in a relatively safer and stable location in South Africa compared to Russia makes platinum's prices more stable and immune to supply shortages. It is recommended that holders of platinum be not worried of economic downturns and should have longer time investing horizons in buying the precious metal. However, this paper cannot conclude the same with palladium prices, because of insignificant result. Comparing the two long-memory models in volatility, the log-likelihood value consistently points to the combined ARFIMA-FIAPARCH models as the best fitting model to characterize both precious metals' prices compared to utilizing the ARFIMA-FIGARCH models. Among the four models utilized, ARFIMA-FIAPARCH models still have the highest log-likelihood values, and FI models or those with long-memory components in the volatility consistently outclassed their short-memory counterparts. The power of FI models over their non-FI counterparts is attributed to the hyperbolic rate of decay present in long-memory models over the exponential rate of decay in short-memory models and the allowance in the difference parameter, which gives greater flexibility in modeling time-series data. These findings have also been documented by Ruzgar and Kale [25] in studying Istanbul stock exchange, Tansuchat et al. [26] using commodity futures, and Goudarzi [27] in the Bombay stock exchange.

\section{Conclusions and Limitations}

This study determines platinum's and palladium's predictability through the long-memory process and safe harbor properties through the asymmetric volatility properties in returns and volatilities. The ARFIMA-GARCH and ARFIMA-FIGARCH models find intermediate memory in the return structures of both platinum and palladium, and both ARFIMA-APARCH and the ARFIMA-FIAPARCH models confirm the result for platinum, but not for palladium. Both models also found long-memory properties in the volatility of platinum and palladium implying the predictability in their volatility structures. With regard to the leverage effects phenomenon, both the ARFIMA-APARCH and ARFIMA-FIAPARCH models confirm the absence of the leverage effects with the significant positive values of the delta $(\delta)$ parameter, which may possibly conclude the resilience of both precious metals against increased volatility. However, further tests proved that only platinum has a symmetric volatility response to shocks with the presence of negative gamma parameter, which is consistent with the earlier findings of ARFIMA-APARCH models further proving that only platinum can be a safe harbor investment, because negative and positive shocks have equal effects on their volatilities.

The economic significance of these results is connected to the more stable demand of platinum from automotive manufacturers, jewelers, and industrial users and to being sourced in a comparatively safer and established location in South Africa compared to Russian mines. The paper recommends that platinum investors be not worried of economic and supply shocks and should have longer investing time horizons in buying the precious metal. Comparing the four models utilized, the log-likelihood value consistently points to the combined ARFIMA-FIAPARCH models as the best fitting model to characterize both precious metals' prices.

The paper acknowledges some limitations that future studies can consider. First, the paper restricted its models in not considering the recent subprime mortgage crisis or other related economic crises for possible structural break tests. Lastly, other econometric methods like that of other FI models like HYGARCH and FIEGARCH can be applied to these precious metals to determine other aspects of the long-memory and leverage effects phenomena, respectively. These limitations can provide future research avenues and can step on the contributions established by this paper regarding the predictability and safe haven properties of platinum and palladium spot prices.

\section{Conflict of Interests}

The author declares that there is no conflict of interests regarding the publication of this paper.

\section{References}

[1] M. E. H. Arouri, S. Hammoudeh, A. Lahiani, and D. K. Nguyen, "Long memory and structural breaks in modeling the return and volatility dynamics of precious metals," The Quarterly Review of Economics and Finance, vol. 52, no. 2, pp. 207-218, 2012.

[2] S. Mabrouk and C. Aloui, "One-day-ahead value-at-risk estimations with dual long-memory models: evidence from the Tunisian stock market," International Journal of Financial Services Management, vol. 4, no. 2, pp. 77-94, 2010.

[3] S. H. Tan and M. T. Khan, "Long memory features in return and volatility of the Malaysian stock market," Economics Bulletin, vol. 30, no. 4, pp. 3267-3281, 2010.

[4] L. Nouira, I. Ahamada, J. Jouini, and A. Nurbel, "Long-memory and shifts in the unconditional variance in the exchange rate euro/US dollar returns," Applied Economics Letters, vol. 11, no. 9, pp. 591-594, 2004.

[5] M. Beine, S. Laurent, and C. Lecourt, "Accounting for conditional leptokurtosis and closing days effects in FIGARCH models of daily exchange rates," Applied Financial Economics, vol. 12, no. 8, pp. 589-600, 2002.

[6] K. Choi and S. Hammoudeh, "Long memory in oil and refined products markets," The Energy Journal, vol. 30, no. 2, pp. 97-116, 2009. 
[7] C. Kyrtsou, W. C. Labys, and M. Terraza, "Noisy chaotic dynamics in commodity markets," Empirical Economics, vol. 29, no. 3, pp. 489-502, 2004.

[8] G. G. Rompotis, "Predictable patterns in ETFs' return and tracking error," Studies in Economics and Finance, vol. 28, no. 1, pp. 14-35, 2011

[9] J. H. Chen and J. F. Diaz, "Spillover and leverage effects of faithbased exchange-traded funds," Journal of Business and Policy Research, vol. 7, no. 2, pp. 1-12, 2013.

[10] J. F. T. Diaz and A. Masa, "Positive dependence and volatility asymmetry properties of the largest exchange-traded notes (ETNs)," Euro-Asian Journal of Economics and Finance, vol. 2, no. 2, pp. 100-107, 2014.

[11] J. A. Batten, C. Ciner, and B. M. Lucey, "The macroeconomic determinants of volatility in precious metals markets," Resources Policy, vol. 35, no. 2, pp. 65-71, 2010.

[12] E. Fama, "Efficient capital markets: a review of theory and empirical work," The Journal of Finance, vol. 25, no. 2, pp. 383$417,1970$.

[13] C. W. Granger and R. Joyeux, "An introduction to long-memory time series models and fractional differencing," Journal of Time Series Analysis, vol. 1, no. 1, pp. 15-29, 1980.

[14] J. R. Hosking, "Fractional differencing," Biometrika, vol. 68, no. 1, pp. 165-176, 1981.

[15] T. Bollerslev, "Generalized autoregressive conditional heteroskedasticity," Journal of Econometrics, vol. 31, no. 3, pp. 307327, 1986.

[16] R. F. Engle, "Autoregressive conditional heteroscedasticity with estimates of the variance of United Kingdom inflation," Econometrica, vol. 50, no. 4, pp. 987-1007, 1982.

[17] Z. Ding, C. W. J. Granger, and R. F. Engle, "A long memory property of stock market returns and a new model," Journal of Empirical Finance, vol. 1, no. 1, pp. 83-106, 1993.

[18] R. Baillie, T. Bollerslev, and H. Mikkelsen, "Fractionally integrated generalized autoregressive conditional heteroskedasticity," Journal of Econometrics, vol. 74, no. 1, pp. 3-30, 1996.

[19] Y. K. Tse, "The conditional heteroscedasticity of the yen-dollar exchange rate," Journal of Applied Econometrics, vol. 13, no. 1, pp. 49-55, 1998.

[20] H. Markowitz, "Portfolio selection," The Journal of Finance, vol. 7, no. 1, pp. 77-91, 1952.

[21] N. Niarchos, Y. Tse, C. Wu, and A. Young, "International transmission of information: a study of the relationship between the U.S. and Greek stock markets," Multinational Finance Journal, vol. 3, no. 1, pp. 19-40, 1999.

[22] B.-N. Huang and C. W. Yang, "Volatility of changes in G5 exchange rates and its market transmission mechanism," International Journal of Finance and Economics, vol. 7, no. 1, pp. 37-50, 2002.

[23] X. E. Xu and H.-G. Fung, "Cross-market linkages between U.S. and Japanese precious metals futures trading," Journal of International Financial Markets, Institutions and Money, vol. 15, no. 2, pp. 107-124, 2005.

[24] J.-H. Chen and C.-Y. Huang, "An analysis of the spillover effects of exchange-traded funds," Applied Economics, vol. 42, no. 9, pp. 1155-1168, 2010.

[25] B. Ruzgar and I. Kale, "The use of ARCH and GARCH models for estimating and forecasting volatility," Kocaeli Üniversitesi Sosyal Bilimler Enstitüsü Dergisi, vol. 14, no. 2, pp. 78-109, 2007.

[26] R. Tansuchat, C. L. Chang, and M. McAleer, Modelling Long Memory Volatility in Agricultural Commodity Futures Returns, 2009.
[27] H. Goudarzi, "Modeling long memory in the indian stock market using fractionally integrated EGARCH model," International Journal of Trade, Economics and Finance, vol. 1, no. 3, pp. 231-237, 2010. 


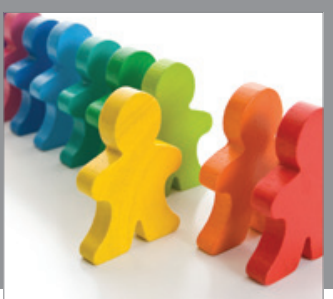

Autism

Research and Treatment
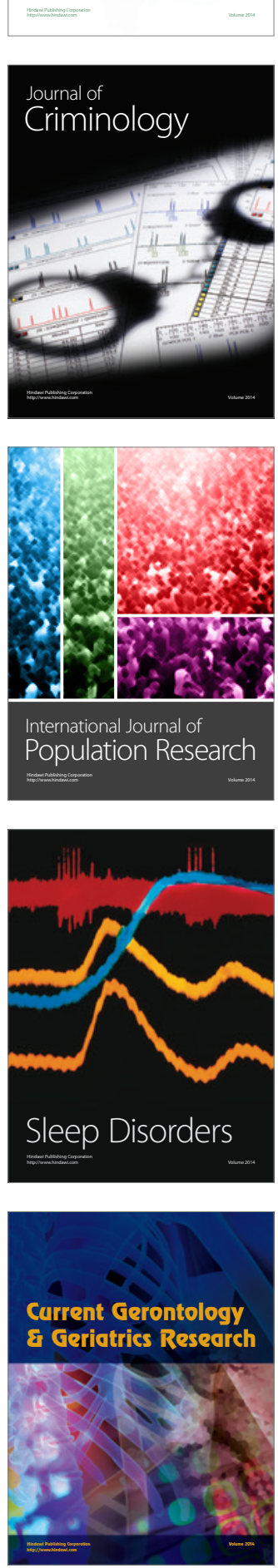

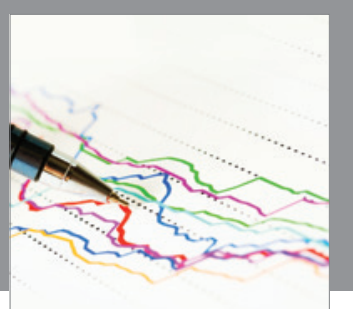

Economics

Research International
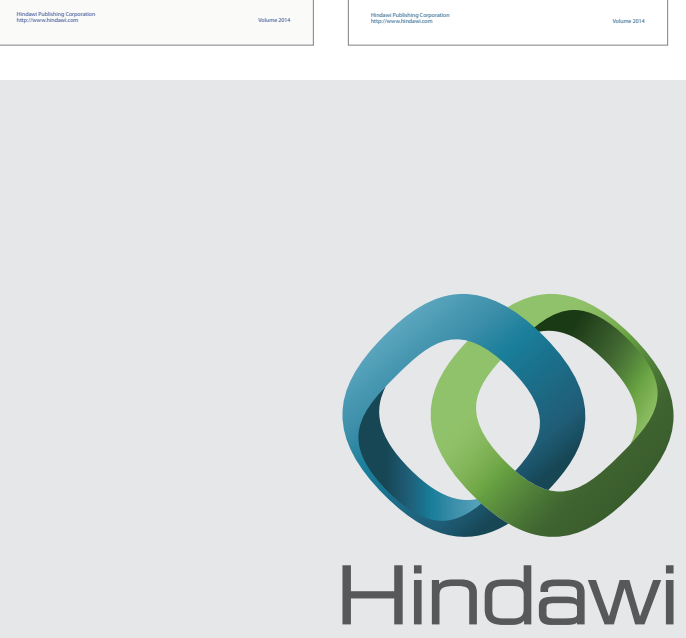

Submit your manuscripts at

http://www.hindawi.com
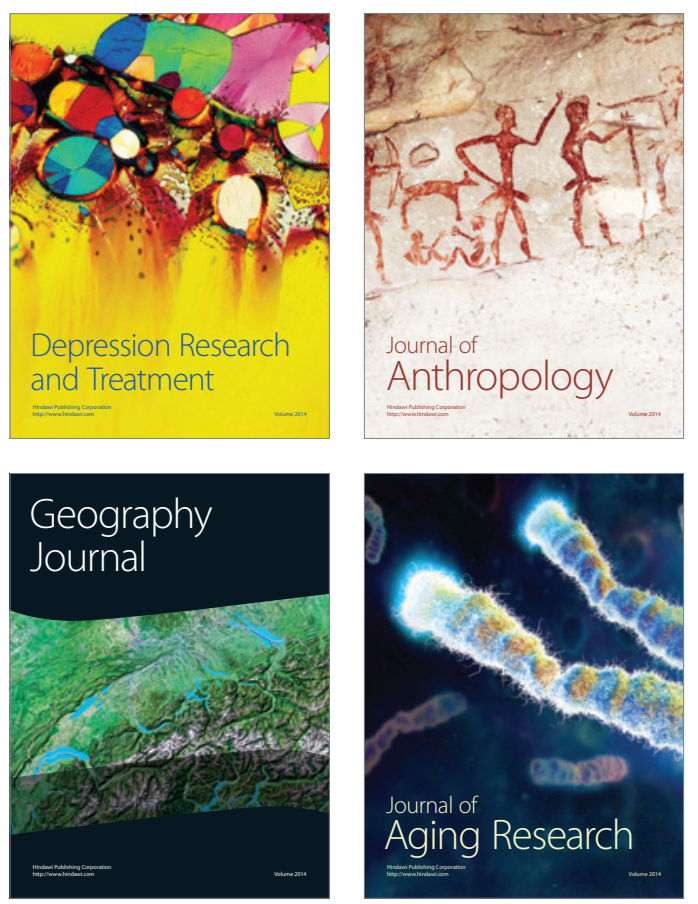
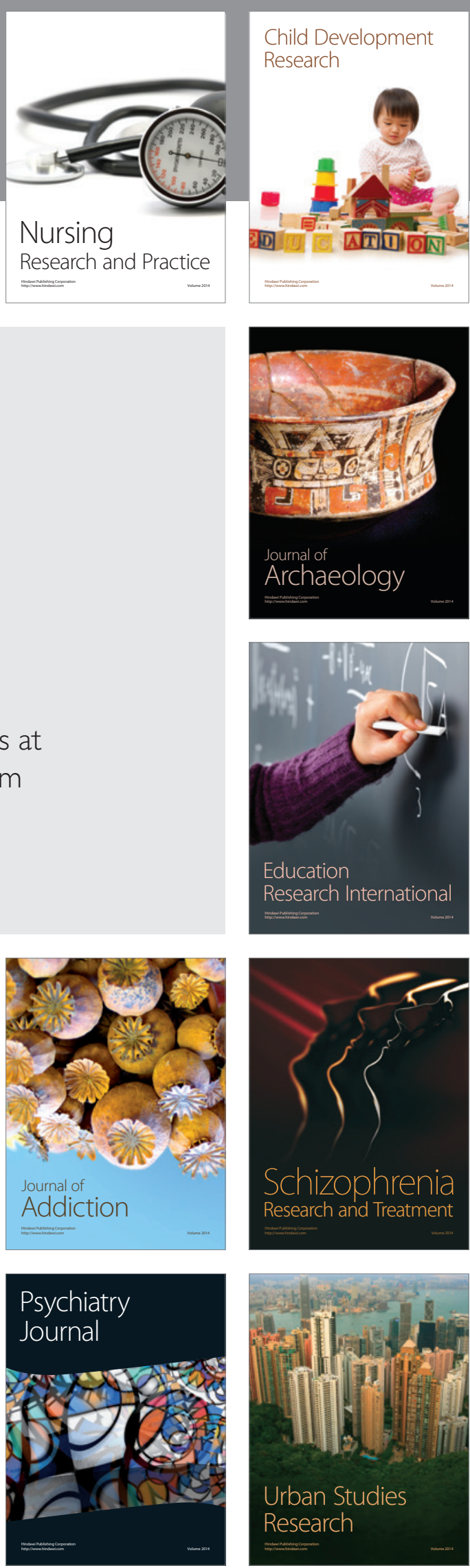